\title{
Simple Underlay Myringoplasty: A Prospective Study
}

\author{
Budhathoki $\mathrm{B}^{1}$, Mishra $\mathrm{SC}^{2}$, Sharma $\mathrm{A}^{3}$
}

\begin{abstract}
Background: Chronic otitis media (COM) is highly prevalent disease encountered by an otologist world wide and also in Nepal. Myringoplasty is the treatment of choice in many cases. There are various techniques of performing myringoplasty with various types of grafts. We propose Simple Underlay Myringoplasty (SUM) using fat graft. Objective: The objective of this study was to evaluate the role of fat graft in closure of small dry central perforations by simple underlay myringoplasty (SUM) with aim to introduce SUM technique in this part of Nepal (Mid Western and Far Western Region). Methods: Young patients above 15 years of age with diagnosis of chronic otitis media, mucosal type with perforations smaller than $50 \%$ of tympanic membrane were included for fat graft myringoplasty. There were total 25 cases included for the study. All the cases were done under local anesthesia. A large single piece of fat, approximately double the size of perforation was harvested from the posterior side of ear lobule. The margin of perforation was freshened. The fat was placed like a dumbbell, equal portion lies medial and lateral to the perforation. Graft uptake results were evaluated after 4 weeks. Results: Graft uptake was successful in 23 patients (92\%). Conclusion: The technique avoids extensive middle ear manipulation and it is safe, simpler procedure for the closure of a dry small central perforation. Its success rate is as good as myringoplasty using temporalis fascia in small central perforations.
\end{abstract}

Key words: Chronic otitis media, fat graft, myringoplasty

\section{INTRODUCTION}

Myringoplasty is one of the most common operations performed by an otolaryngologist. Temporalis fascia is the most common material used for the closure of tympanic membrane perforation. Berthold ${ }^{1}$ in 1878 used a full-thickness free skin graft for tympanic membrane closure. Ringenberg used a fat tympanoplasy for the first time for the closure of a small tympanic perforation ${ }^{2}$. The fat graft tissue tympanoplasty has certain advantages as this procedure can be done on an outpatient basis. The patient goes home on the same day with very limited postoperative care. Fat can be harvested in a very short time and it avoids invasive extensive surgical manipulation of the middle ear. ${ }^{3}$

It is a simple and cost effective technique in managing small tympanic membrane perforation and the success rate of a fatplug myringoplasty is comparable with the results of temporalis fascia tympanoplasty. ${ }^{4}$ The aim of this study was to evaluate fat

\footnotetext{
1. Dr. Bikram Budhathoki

2. Prof. S. C. Mishra

3. Dr. Anshu Sharma
}

\section{Address of correspondence:}

Dr. Bikram Budhathoki

Department of E.N.T.

Nepalgunj Medical College Teaching Hospital

Kohalpur, Banke, Nepal

E-mail: bikki37@gmail.com graft uptake rate in small central tympanic membrane perforations. To the best of our knowledge, the present study is first of its kind in Mid Western and Far Western Region of Nepal.

\section{MATERIALS AND METHODS}

It was a prospective, longitudinal study conducted at Nepalgunj Medical College Teaching Hospital, Kohalpur, Nepal from January 2013 to February 2014. Total 25 cases were included in this study with age greater than 15 years, all gender, patient with chronic otits media mucosal with less than $50 \%$ central perforation of tympanic membrane and hearing loss less than $30 \mathrm{~dB}$. Perforation more than $50 \%$, active mucosal disease and hearing loss more than $30 \mathrm{~dB}$ were excluded from this study.

\section{Surgical Technique}

All the cases were done under local anaesthesia with $4 \%$ xylocaine soaked cotton ball placed over tympanic membrane to block tympanic plexus. All the cases were done via permeatal approach and done by first author. Tympanomeatal flap was not elevated in this technique in contrast to conventional myringoplasty. Around $2 \mathrm{ml}$ of $2 \%$ xylocaine was injected on the posterior surface of the lobule and a small incision was made on the posterior aspect of the ear lobule. A single piece of fat, approximately twice the size of the perforation, was harvested (Figure 1) taking care not to make a buttonhole on the anterior surface of the lobule. The skin incision was sutured with silk 4-0. Using the operative microscope, the margin of the perforation was trimmed and de-epithelialized using a sickle knife (Figure 2). Small pieces of gelfoam were placed in the middle ear through the perforation. The piece of fat was positioned in such a way that equal proportion lied medially and laterally to the tympanic membrane and fit the 
perforation snugly like a dumb-bell (Figure 3). The fat plug was overlaid with antibiotic soaked gelfoam. These gelfoam pieces prevent the displacement of the fat plug by supporting it from the both sides. The closure of the perforation (Graft uptake) was considered successful for a fat-plug myringoplasty after 4 weeks follow up.

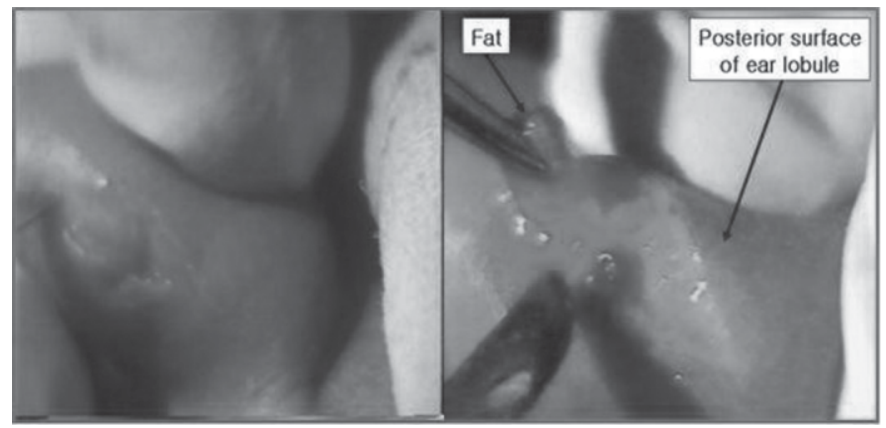

Figure 1: Incision on the posterior surface of the lobule and fat harvesting

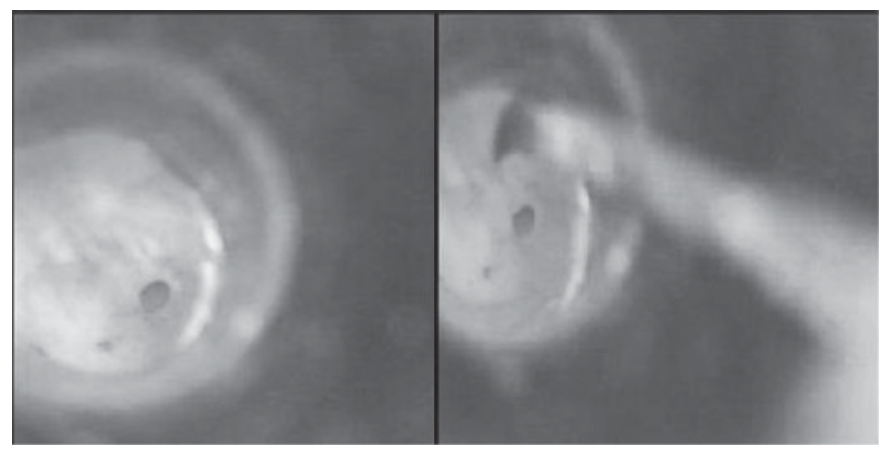

Figure 2: Small central perforation and using sickle knife to freshen the edges of perforation

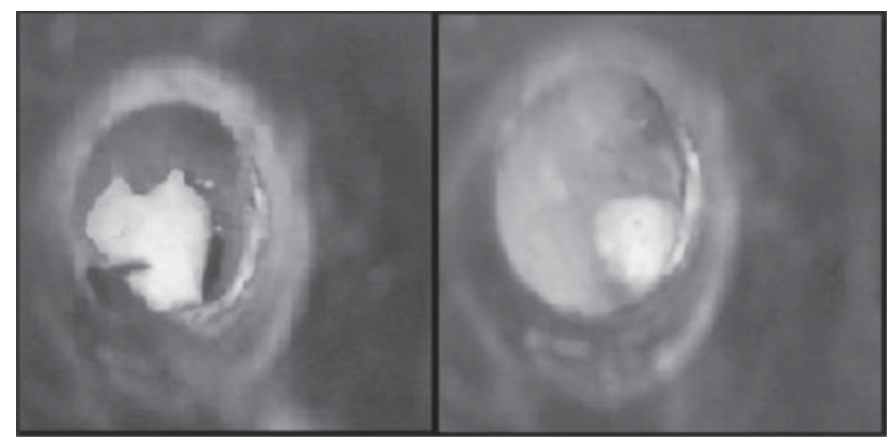

Figure 3: Figure 3: Fat plugging the perforation

\section{RESULTS}

There were total 25 cases included in this study. Among them, 15 patients were male and 10 patients were female. Twentythree patients had complete closure of the tympanic membrane perforation while two patients had residual perforation after one month follow up. Overall success rate in our study was $92 \%$. Average time for the procedure was only 20 minute

\begin{tabular}{|l|c|c|}
\hline \multicolumn{1}{|c|}{ Author (Reference) } & $\begin{array}{c}\text { No. of } \\
\text { cases }\end{array}$ & $\begin{array}{c}\text { Success } \\
\text { rate }\end{array}$ \\
\hline Liew, et al., 2002(5) & 15 & $100 \%$ \\
\hline Ayache, et al., 2003(6) & 45 & $91.9 \%$ \\
\hline Hagemann \& Hausler, 2003(7) & 44 & $91 \%$ \\
\hline Ozgursoy \& Yorulmaz, 2005(3) & 18 & $82.4 \%$ \\
\hline Present Study 2015 & 25 & $92 \%$ \\
\hline
\end{tabular}

Table I: Results of myringoplasties with fat graft

\section{DISCUSSION}

The overall success rate in our study was $92 \%$ which is comparable with the study of Liew et al $^{5}$ who used adipose tissue in the persistent perforation following tympanostomy tube removal (Table I). He had a $100 \%$ success rate in his series of 15 children. He harvested fat by placing a small horizontal incision along the inferior aspect of the lobe. Ayache et $\mathrm{al}^{6}$ harvested fat from the abdomen, making a separate skin incision close to the center of the umbilicus, in $91 \%$ of the cases and from the pretragal area in $9 \%$ of the cases. They also affixed the fat with biologic glue. Hagemann and Hausler found a $91 \%$ success rate in their large study. Though in our study of 25 cases with $92 \%$ success, we propose a bigger study to establish its success rate. We restricted our case selection to those perforations with a size of less than $50 \%$. The larger perforation was avoided for this type of procedure due to the possibility of failure.

Dedden et $\mathrm{al}^{8}$ found that the size of the perforation is a crucial factor and $30 \%$ of the drum surface is a good prognostic factor for the fat graft. Perforations larger than one quadrant of the tympanic membrane are unfavorable for the insertion of the fat plug. ${ }^{2} \quad$ All our cases had the perforation in the antero inferior and postero inferior quadrant of the tympanic membrane and the success rate was not related with any particular quadrant of the tympanic membrane as shown in the result. It is important to note the property of the fat tissue for the fat tympanoplasy procedure. Although it can be harvested from the abdomen, buttock and ear lobule, the ear lobule fat harvesting is much simpler than the other sites. It can be harvested from the same sterile area of surgical field prepared for the fat tympanoplasy. Its scar is almost invisible as incision is given on the posterior 
aspect of lobule. The fat of ear lobule is denser and has better epithelial and mucosal tympanic growth. It presents a big revascularization activity ${ }^{2}$ as seen by otoscopy a few days after the procedure. There is significant bulging on the tympanic membrane $e^{3}$ till the end of the third month postoperatively and after three months bulging of the fat graft progressively disappeared and converted into a smooth sclerotic area on the tympanic membrane at the fifth month. This findings were also seen in all our successful patients in the postoperative period of 1-3 months. There are two histological theories of fat grafts. ${ }^{9}$ The host cell replacement theory' of Neuhof ${ }^{10}$ and 'The cell survival theory' of Peer. ${ }^{11}$

The host cell replacement theory states that all the original cells die and are totally replaced by new wandering adipocytes or by fibroblasts. The cell survival theory states that not all the original adipose cells die. Those fat cells which receive adequate blood supply survive whereas remaining degenerate, thus explaining loss of volume. The transplanted fat cells are not replaced by scar tissue, instead a connective tissue capsule outside the fat graft begins three weeks after transplantation, which becomes progressively thinner over the course of a year. Fat tissue provides the basic requirement for the grafting of the tympanic membrane with its own favorable characteristics. ${ }^{3}$

\section{CONCLUSION}

The temporalis fascia is the most common material used for tympanoplasty. However, myringoplasty, using fat graft is a quick procedure and avoids middle ear manipulation. The harvesting of fat tissue is easy. Patient can be discharged on the same day with minimal postoperative care. Thus we propose that Fat-plug myringoplasty is easy, require less surgical time, cost effective with the success rate as good as with myringoplasty using temporal fascia for the small dry central perforation.

\section{REFERENCES}

1. Berthold E. Uber Myringoplastic. Med-chir centralb. 1879; 14: 195-207.

2. Ringeberg JC. Fat graft tympanoplasty. Laryngoscope. 1962; 72:188-92.

3. Ozgursoy OB. Yorulmaz. Fat graft myringoplasty: a costeffective but underused procedure. The journal of laryngology \& Otology. 2005;119:277-79.

4. Gross CW. Bassila M. Lazar RH. Long TE. Stagner S. Adipose plug myringoplasty: an alternative to formal myringoplasty techniques in children. Otolaryngol Head Neck Surg. 1989; 101: 617-20.

5. Liew L. Daudia A. Narula AA. Synchronous fat plug myringoplasty and tympanostomy tube removal in the management of refractory otorrhoea in younger patients. International journal of pediatric Otorhinolaryngology. 2002; 66:291-96.

6. Ayache S. Braccini F. Facon F. Thomassin JM. Adipose graft: An original option in myringoplasty. Otology \& Neurotology. 2003; 24:158-64.
7. Hagemann M. Hausler R. Tympanoplasy with adipose tissue. Laryngoscope. 2003; 82:393-396.

8. Deddens AE. Muntz HR, Lusk RP. Adipose myringoplasty in children. Laryngoscope. 1993; 103: 216-219.

9. Boyce RG, Nuss DW, Kluka EA. The use of autogenous fat , fascia, and nonvascularized muscle grafts in the head and neck. Otolaryngol Clin North Am. 1994; 27: 39-68.

10. Neuhof H. The transplantation of tissues. New York, D Appleton, 1923; 74.

11. Peer, L.A. Transplantation of tissues, Vol 2. Baltimore: Williams \&Wilkins, 1959; 73. 